consisted of a camnon-ball wcighing about 5 lbs., suspended by a fine steel wire, which at its upper end passed through a hole drilled in an iron plug. 'The pendulum would continue to vibrate for sixteen or eighteen hours after being set in motion. After obtaining satisfactory results by using a ring of sand in the ordinary manner, a very stiff bristle was attached to the terminal spindle, and under it was placed a thin smoked-glass plate. The resistance was too great to allow the bristle to strike against the plate at each vibration of the pendulum, so that the device was adopted of fixing the plate upon a heavy brass disk capable of being raised or lowered by levelling-screws. This was placed under the pendulum before the latter was set in vibration, and then carefully raised until the bristle scratched its trace on the smoked-glass plate. After two or three oscillations of the pendulum the plate was lowered, great care of course being taken to avoid all possibility of rotation during this operation. At the expiration of fifteen, thirty, or sixty minutes it was again raised, and this process was repeated as often as desired. The inclination of the tracings was beautifully shown, and its amount agreed exceedingly well with that given by theory. With a heavier ball and longer wire even better results might have been obtained, but the motion of the pendulum used was but very slightly interfered with by the friction of the bristle. I should not omit to mention that the details of the experiment were carried out by Mr. F. W. Very, then a student at the institute.

Boston, Mass., June I9

\section{The Freshwater Medusa}

In Nature, yol. xxii. p. 218 , Prof. Allman by mistake attributes to me the conclusion that Limnocodium has no marginal canal, and that its radial canals are not pervious. $\Lambda$ reference to NATURE, vol. xxii. p. 147, will show that in my first publication on the subject I gave as a character of the new genus Radiating canals 4, opening into the marginal canal. Marginal or sag caral voluminous." I made the same statement in my communication to the Royal Society on June 17 , and have not since deviated from it.

E. RAY LANKESTER

\section{Artificial Diamonds}

THE process of building up tubes, which Mr. Mallet has leen so kind as to suggest to me through your valuable journal, has been tried, but was unsuccessful through the same defect a caused the failure of many of my other experiments, namely, lealiage without bursting. Some of the tubes found empty would bear, when cold, a pressure of ten tons on the square inch without leaking, showing that the gases escaped through the porosity of the iron at a high temperature. Iydrogen and hydrocarbons secm to go through iron at a red heat very easily, and the direction in which I am working is to obtain an impervious coating, or a method of "clogging" the iron, as seems to have sometimes taken place in the carbon experiments.

Experiments conducted since the reading of my paper have convinced me that the crystallisation of silica and alumina may yet be carried out with case and certainty, and when I have rendered one of thesc processes a commercial success the experience gained in daily manufacturing operations will enable me to attack the carbon problem with much more certainty of obtaining definite results.

As I shall be writing an account of this work in the autumn I shall feel greatly indebted to any of your readers who, if they come across any not widely known experiments in this direction, will kindly communicate with me, so that I may have all the work don 2 in this direction before me. Suggestions such as $\mathrm{Mr}$. Mallet's a:e valuable to any worker, as the reactions of one brain must always be somewhat similar unless outside stimuli give new directions to its activity. I am always therefore thankful for either suggestion or corrections.

Private Laboratory, Glasgow

\section{Temperature of the Breath}

THE average temperature of the interior of the human body, according to our best authorities, is $n 8^{\circ} 6 \mathrm{~F}$. What is the temperature of the breath? It might naturally be supposed that it; temperature was the same as that of the interior of the body, or lower, if it is derived from the lungs, into which it is drawn from the cold outer air. J3ut is this so?
The temperature of my body, as shown by the thermometer in the axilla and moutb, is normal, i.c., about $982^{\circ}$. On rising in the morning, before dressing or eating, I take the thermometer, wrap it up tightly in several folds of a silk handkerchief, and breathe upon it (expiring through the silk immediately over the bulb of the thermometer and inspiring by the nostrils). After five minutes of this operation I examine the thermometer, and find that it indicates a temperature of $106^{\circ} 2$. At 7 p.m., after brisk walking cxercise, having eaten nothing since breakfast except a spoonful of boiled rice at $I$ p.m., and having drank nothing but half a tumbler. of water and a monthful of ginget. beer, I take the temperature of my breath in the manner described, for five minutes. I find the thermometer indicates $107^{\circ}$. Again, immediatcly after dinner, at which only water was drunk, the thermometer shows my breath to have a temperature of $108^{\circ}$. At other times the thermometer will not rise under apparently the same conditions higher than $102^{\circ}$ to $105^{\circ}$. A temperature of $109^{\circ}$ was observed by the correspondent of an American journal, but he does not mention under what cireum. stances this occurred.

How is this high temperature produced? It cannot, as a friend suggested to me, be caused by the condensation of the moisture in the breath by the silk handkerchief, for if the temperature of the breath as it issues from the lungs be the same as that of the lungs themselves, i.e., not exceeding $99^{\circ}$, the silk, soon becoming much hotter, would rather teni to vola tilise than to condense the moisture of the breath. Is it caused liy the friction of the breath upon the fibres of the handkerchief? I know of no observations to show that a ligh temperature twould be so caused. Is it the actual temperature of the breath as it issues from the lungs? If so, then it is by the breath that the system gets rid of its superfluous caloric. For this elevated temperalure is not communicated to the blood oxygenated in the lungs ; the blood in the left ventricle of the heart (which receives this oxygenated blood) being, according to some physiologists, lower in temperature than the blood in the right ventricle, which has not yet entered the lungs.

The few cxpcriments I have made seem to show that the temperature obtained as above described is higher when the surrounding air is warm than when it is cold. This looks as if norc caloric passed off by the breath when less can escape from the general surface of the body.

Iow these high temperatures are produced in the lungs, if they are developed there, is a mystery. Perhaps some of your readers may be able to explain.
53 , Montagu Square, May 27
R. E. DUdGeX

\section{Reversals by Memory}

I sHoUl. much like to know if it be a common thing for people to revers: the positions of cibjects in the memory. An artist, on returning from the National Gallery, painted the Timisraire from memory. Taking his picture to compare it with 'Iurner's, he found to his surprise that he had reversed the positions of the ship, tug, sun, Sc. III daughter tells me that if she wants to refer to a passage in a book she as often looks for it on a left-hand page, while it is on a right-hand page, or vice versa. Another lady, on looking at a wood-engraving made from a sketch which she had seen some time previously, asked if the engraver had not reversed everything? These are the only cases known to me.

Is the following universally true?-

Let some one write with a blunt instrument the letter $P$ on your forehead, or anywhere on the front half of the head from ear to ear, and the P nust be written backwards for you to "see" it correctly. But if it be written anywhere at the back of the head, it must be written correctly both for you and the writcr to read it. The change takes place abruptly in a line orer each car.

(xFORGE HFNSLOW

\section{Toughened Glass}

TIL night before last a lady of my family emptied a paper powder composed of $7 \frac{1}{3}$ grains of carbonate of potash and $7 \frac{1}{3}$ grains of carbonate of soda into a tumbler of what is called toughened glass less than balf full of cold water. After stirring the mixture she drank the contents, leaving a silver tea-spoon in the tumbler, and then placed the empty tumbler on the table by her side within perhaps a font of a burning duplex lamp. Ab'ut five minutes afterwards a sharp explosion occurred, which startied 